\title{
Dual-function ZIF-8 membrane supported on alumina hollow fiber membrane for copper(II) removal
}

\author{
Dayang Norafizan binti Awang Chee ${ }^{\text {a,b }}$, Farhana Aziz ${ }^{\text {a, }}$, Ahmad Fauzi Ismail ${ }^{\text {a, , }}$ \\ Mohamed Afizal bin Mohamed Amin ${ }^{\text {a,c }}$, Mohd. Sohaimi Abdullah ${ }^{\text {a }}$ \\ ${ }^{a}$ Advanced Membrane Technology Research Centre (AMTEC), School of Chemical and Energy Engineering, Faculty of Engineering, Universiti Teknologi Malaysia, \\ 81310, Johor Bahru, Johor Darul Takzim, Malaysia \\ ${ }^{\mathrm{b}}$ Faculty of Resource Science and Technology, Universiti Malaysia Sarawak, 94300 Kota Samarahan, Sarawak, Malaysia \\ ${ }^{\mathrm{c}}$ Department of Chemical Engineering and Energy Sustainability, Faculty of Engineering, Universiti Malaysia Sarawak, 94300 Kota Samarahan, Sarawak, Malaysia
}

\section{A R T I C L E I N F O}

Editor: Dr. GL Dotto

\section{Keywords:}

ZIF-8 membranes

Alumina

Natural-based materials

Copper(II) removal

Adsorptive membranes

\begin{abstract}
A B S T R A C T
The as-spun alumina hollow fiber membrane was used as membrane support for the development of ZIF-8 membrane. The ZIF-8 layers were successfully grown on the support by using the in-situ solvothermal method and layer-by-layer method. The morphology and physicochemical properties of the membranes were characterized using the field emission scanning electron microscope (FESEM), X-ray diffraction spectrophotometer (XRD), Fourier-Transform Infrared Spectrophotometer (FTIR). The adsorption study revealed that the removal of copper(II) ion was $\mathrm{pH}$-dependent. The adsorption capacity for copper(II) adsorption is $76.5 \mathrm{mg} / \mathrm{g}$. The adsorption mechanism of copper(II) onto the ZIF-8 membrane was best fitted to the Freundlich isotherm and pseudo-secondorder model. The filtration study showed that the membranes could remove up to $90 \%$ of copper(II) ions from the aqueous solution.
\end{abstract}

\section{Introduction}

Water is the source of life. Each person on Earth needs at least 20-50 $\mathrm{L}$ of clean water for daily activities, including drinking, cooking and cleaning. Consuming polluted water is a major concern and need to be taken care of because it might cause death to human and life-beings. The industrialization has grown at a very fast rate, contributed to the demand for natural resources. The mining activities have led to environmental pollution due to the release of inorganic ions, organic pollutants, organometallic compounds, radioactive isotopes and nanoparticles [1].

Heavy metal wastewater originated from urbanization and industrialization activities, leading to heavy metal accumulation in the water bodies. The high solubility of heavy metals in aquatic environments leads to the high potential to be absorbed by living organisms. Thus, the accumulation of heavy metal throughout the food chain will cause harmful effects, especially to humans, as the concentration will increase along the food chain. The common heavy metals present in industrial wastewater include nickel, zinc, silver, lead, iron, chromium, copper, arsenic, cadmium and uranium [2]. However, copper was found to be in higher concentrations among all the heavy metals because it is commonly used in industrial applications. The United State Environmental Protection Agency (USEPA) has determined that drinking water should have less than 1.3 ppm of copper [2].

Several methods and techniques were reported previously on the removal of copper ions from wastewater, for example, the adsorption [3-5], photocatalysis [6], electrochemical [7], chemical precipitation $[8,9]$, ion exchange [10] and flotation $[11,12]$. Although a vast number of techniques were employed for copper(II) removal, new technologies with better performance and advantages still being searched to overcome some advantages from the previous method, for instance, the incomplete removal, high energy requirements and the production of toxic waste after the treatment [13]. Therefore, membrane technologies come into the picture to facilitate the removal of pollutants and water recovery.

In the present study, alumina hollow fiber membrane, derived from natural-based material known as alumina, was selected as a support membrane. Alumina is a naturally occurred aluminium oxide, found in the environment as minerals known as corundum, diaspore and gibbsite [14]. Alumina originated from bauxite, the impure form of gibbsite. The bauxite undergoes extraction process to purify the compounds into a

\footnotetext{
* Corresponding authors.

E-mail addresses: farhana@petroleum.utm.my (F. Aziz), afauzi@utm.my (A.F. Ismail).
} 